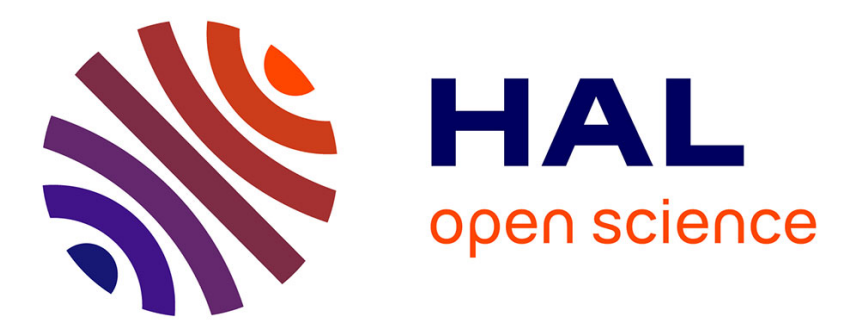

\title{
An expandable mechanism for deployment and contact surface adaptation of rover wheels
}

Philippe Bidaud, Faiz Ben Amar, Sebastien Poirier

\section{To cite this version:}

Philippe Bidaud, Faiz Ben Amar, Sebastien Poirier. An expandable mechanism for deployment and contact surface adaptation of rover wheels. 8th International Conference on Climbing and Walking Robots and the Support Technologies for Mobile Machines (CLAWAR 2005), 2005, Londres, United Kingdom. pp.1053-1060, 10.1007/3-540-26415-9_126 . hal-03178085

\section{HAL Id: hal-03178085 \\ https://hal.science/hal-03178085}

Submitted on 23 Mar 2021

HAL is a multi-disciplinary open access archive for the deposit and dissemination of scientific research documents, whether they are published or not. The documents may come from teaching and research institutions in France or abroad, or from public or private research centers.
L'archive ouverte pluridisciplinaire $\mathbf{H A L}$, est destinée au dépôt et à la diffusion de documents scientifiques de niveau recherche, publiés ou non, émanant des établissements d'enseignement et de recherche français ou étrangers, des laboratoires publics ou privés. 


\title{
An expandable mechanism for deployment and contact surface adaptation of rover wheels
}

\author{
Philippe Bidaud, Faiz Benamar, and Sébastien Poirier \\ Laboratoire de Robotique de Paris \\ Université Paris 6 / CNRS \\ 18, route du Panorama \\ 92265 Fontenay Aux Roses - France \\ bidaudOrobot.jussieu.fr
}

\section{Abstract}

In this paper, an expandable mechanism for unfolding wheels is proposed. This mechanisms combines 2 elementary mechanisms. One allows the deployment of the rim the other one ensuring the contact shape adaptation.

\section{Introduction}

Mars exploration programs that require surface mobility, such as geology studies, search for past life or infrastructure deployment for future manned missions, make use of wheeled rovers. The total mass of the rover and its volume during launching phase are very constrained, thus resulting in moderate ability to overcome obstacles, despite the efforts in optimizing the kinematics design, due to the limitations on wheel diameter. Meanwhile, the wheel size is one important parameter that determines the rover crossing performances. These limitations can be reduced by introducing mobilities in the system for the deployment of the locomotion mechanism from a stowed configuration or/and using inflating or unfolding wheels that can reach large diameters and thus present high cross-country ability, still being compatible with the launching constraints. The adaptation of the contact surface geometry of the wheels is another important feature which will allow to optimize traction and mobility performances of non-holonomic vehicles with respect to the physical characteristics of the ground. One of the purpose of the INTAS Project untitled Innovative Mars exploration rover using inflatable or unfolding wheels is to study mechanically deployable wheels and compare them with classical rover 
wheel design, given the same mission objectives and constraints. Many sorts of deployable structures exist, based on a variety of different concepts. Some of these structures form planar or space frames and have already had a variety of applications [3] [5] : space applications for solar arrays, solar sails, etc or architecture applications to support membranes or films. The most impressive example of these deployable structures are certainly retractable roofs within the field of architecture. The paper describes a new type of expandable mechanisms with 2 degrees of freedom (dof). This mechanism combines 2 elementary mechanisms which allows the deployment of the rim the other one ensuring the modification of the rolling tread geometry. To obtain this expandable mechanisms, planar linkages with 1-dof have been design and optimized in their kinematics to obtain the desired expansion ratio for the former one and its rigidity under a radial load for the other one. These planar units are then assemble to form the desired "solid".

\section{Deployable mechanisms}

Reversible foldable mechanisms are such that their structure remains stress free throughout the deployment. They are capable of expanding from a closed, compact configuration to a pre-determined while modifying their dynamics. They can be classified as follow :

1. structures with rigid 1-D bars connected to each other in various pantographic arrangements of $2-\mathrm{D}$ and $3-\mathrm{D}$;

2. structures with 2-D panels connected to form various surface structures, basic element being a triangular panel [4];

3. tension structures consisting of cables or membranes, or combination of both, either pre-stressed or pneumatic [5];

4. deployable tensegrity structures composed of rigid rods and cables [6];

The two last one combine are said form-active systems since they allow to create a structure that could autonomously adapt both its shape and its mechanical behavior. This idea will be reused for the design of the " 'casing of the tire"' in the deployable wheels proposed in this paper.

Several bar mechanisms have been invented to create reversible foldable structures along its external perimeter or surface. Most of them are made of hinges and pivots and are able to move in a plane, along a cylinder or sphere.

Emilio Pinero pioneered the use of scissor mechanisms to make deployable structures Scissor hinge structures built out of basic units composed 
of rod elements connected in there center and with each other by hinges. The basic unit (a Scissor-Like Element) is a pantograph. These units can be assembled to form an opened or a closed loop system with a single degree-of-freedom. Fig.1 considers different planar arrangements of parallel straight or angulated rods. Space frames can be formed by closed
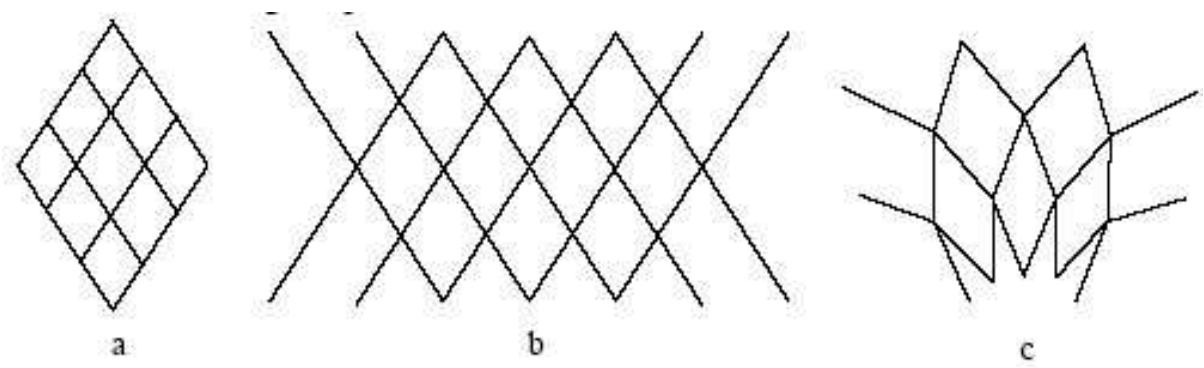

Fig. 1. Multiple scissor-like elements with straight rods or angulated rods

loops of these elements. Fig.2 shows an example of a mechanism which was adopted in the edge beam of the Hoop-Column Antenna [2] and built with half-scissor mechanisms. This kind of structure must have an even number of equal-length hinged segments with a rotoid joint at each extremity whose axis is orthogonal to the segment. Here, the joints of 2 consecutive segments are not collinear but form an angle in the plane perpendicular to the symmetry axis of the structure. It can be checked that due to its particular geometric properties, the mobility of this mechanism is equal to 1 . Hoberman has also created numbers of pantograph mech-

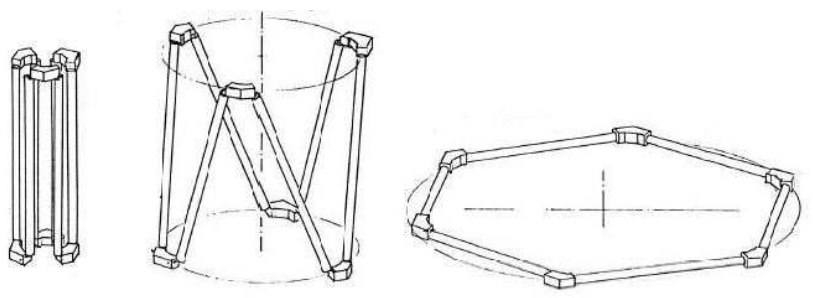

Fig. 2. Half-scissor closed-loop deployable mechanism

anisms that operate in two and three dimensions. A " $N$-gon" as shown in Fig.3 can expand out in a symmetric manner by "actuating" only on of its members [7]. When scissors-pairs are connected in closed-loop via 
angulated elements in such way that the normal line that are perpendicular to the axis of the joined terminal pivot of adjacent scissors-pair intersect, a reversible folding of the structure takes place without internal constraints in the structure.

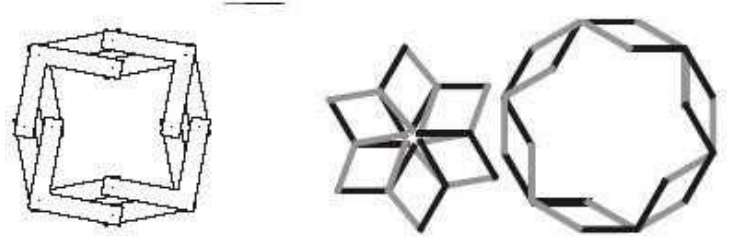

Fig. 3. Expanding " 4 -gon"' and "6-gon"' based on Hoberman design
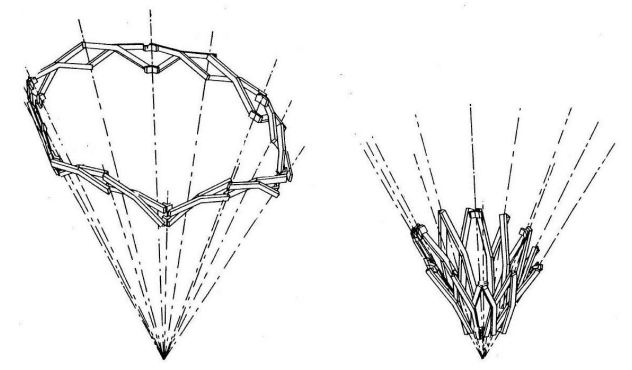

Fig. 4. Configuration where the pivot points of all the scissor-pairs lie on a circle

\section{Proposed mechanism design}

The mechanism which has been designed for creating the deployable wheel with a contact shape adaptation can be decomposed in 2 subsystems.

1. a mechanism for the radial expansion of the wheel rim,

2. a mechanism for deformation of the contact surface geometry.

Fig.5 shows the deployment of the wheel at 3 different stages.

\subsection{The spokes}

Its has been designed in the aim to have shape for the wheel similar to the one of the Marshokod robot [1]. The expansion of the rim is based on 


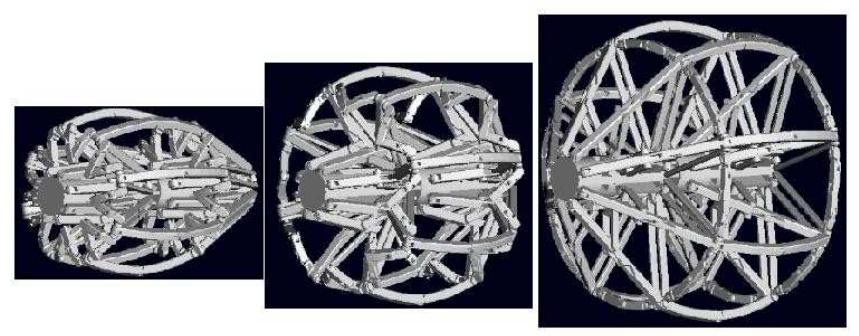

Fig. 5. Folding/unfolding process at 3 different stages. On the left the "open"' configuration

the use of a set of identical planar mechanisms disposed radially which play the role of spokes. Each of these mechanism can be seen as a parallel mechanism whose limbs are imbricated 4-bars mechanisms (see Fig.6). The inputs are the linear motions of points $A_{1}$ and $A_{2}$ which are coupled to the same linear actuator placed in the hub of the wheel. When these

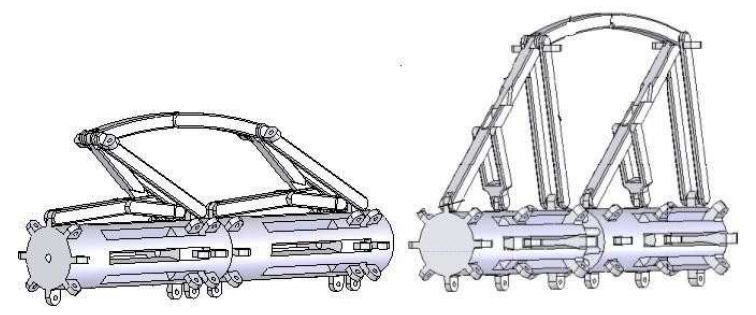

Fig. 6. Mechanism for the expansion of the rim

"spokes"' are totally deployed, the mechanism is in a stationary configuration. This local singularity happens when the coupling bar is parallel to the upper bar of the 4-bars mechanism. Therefore, the mechanism becomes an immovable structure regardless of the input. Moreover, in this configuration the actuator does not work in any external force applied on the upper 4-bars mechanism.

\subsection{The rim}

The rim itself is a loop-assembly of rigid 2-bars (a rim sector) joining consecutive spokes, each rim sector being articulated on a spoke by a universal joint. Fig. 7 shows the deployment of a rim sector simultaneously to the deployment of the spokes. 


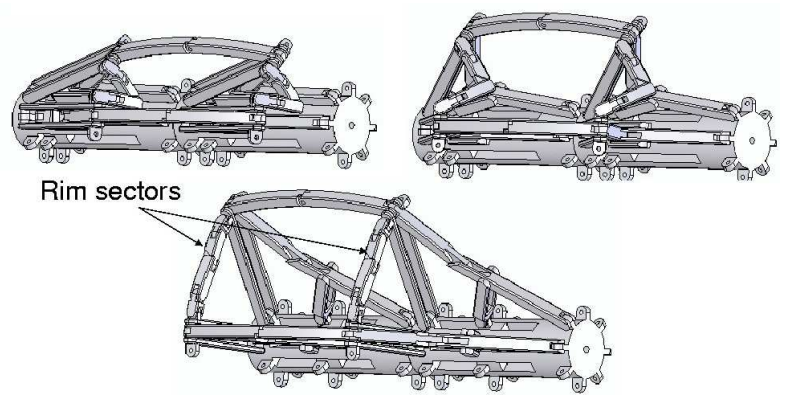

Fig. 7. Deployment of the rim sectors

\section{Contact geometry adaptation}

The adaptation of the contact geometry has been envisaged by articulating each strut which form the carcass-element (the rib) with a pivot placed at its mid-length. The actuator placed in the hub of the wheel which actuates the deployment will then be used for driving the translation of the 2 parallel rimes with their spokes (see Fig.8). So, the angle formed between the two parts of the carcass-element will be modified and consequently the local geometry of the rolling tread as well as the compliance of the contact.

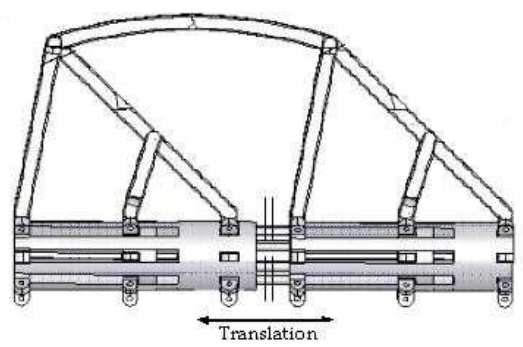

Fig. 8. Mechanism for the control of the carcass-element geometry

\subsection{Stiffness analysis}

Exposed to a vertical load and a traction force, the carcass will deform. A precise estimation of its deformation has be performed using a finite element linear analysis (FEA) on an isolated radial element. This analysis have been made by using COSMOSWorks design analysis software that is fully integrated in SolidWorks. Schematically, the factors affecting 
the contact stiffness are the shape (and material) of the carcass-element and its support (the deployment mechanism). In Fig.9 are displayed the results of the analysis in von Mises stress and represented in a graphical manner. A uniform vertical and ortho-normal load are applied to the carcass-element to emulate a load of $40 \mathrm{daN}$ and a traction of $17 \mathrm{daN}$. The maximum stress for a is $1.810^{8} \mathrm{Nm}^{-2}$ for aluminum alloy parts of section $10 \times 10 \mathrm{~mm}^{2}$. The possible deformation the carcass-element may achieved with these loading conditions is shown in Fig.9. It stays very small (less than $1 \mathrm{~mm}$ ) and is not enough important to produce a tangential force.

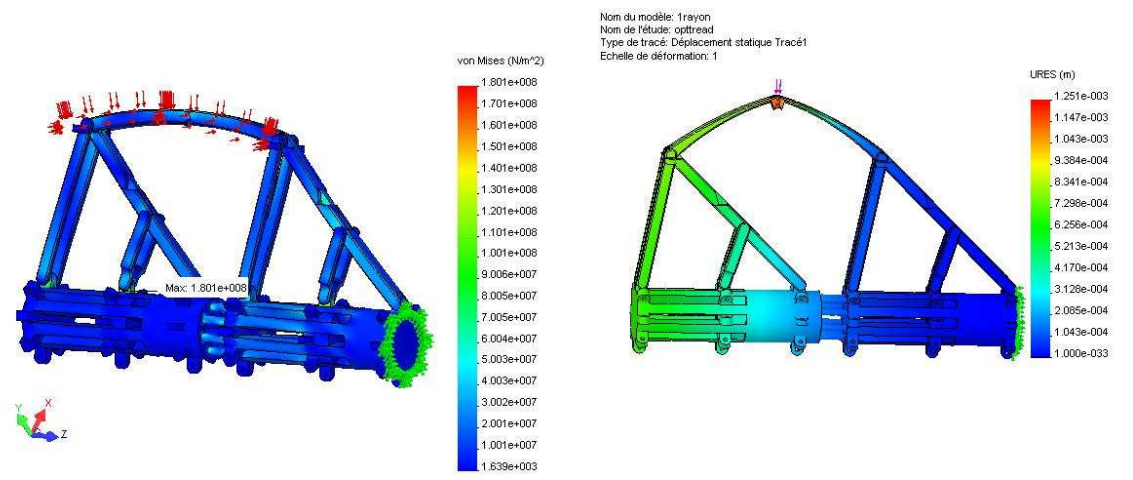

Fig. 9. Display of von Mises stress results (right) and displacement analysis result plot (left)

To increase the carcass deformation, an alternative design for the carcass-element using an arched beam have been explored (see Fig.10). A smooth deformation between a geometry of the carcass corresponding to a well-inflated tire and a poorly-inflated tire can be controlled by the contact-variation mechanism described above. The amount of change in carcass shape remains important when using glass-fiber composite materials. Its deformation under a vertical load and its dynamical properties are much more closer to a classical inflated tire.

\subsection{Conclusion}

This paper has presented an original mechanism designed for creating a deployable wheel with a contact shape adaptation. As far as we know, this is the first time an unfolding wheel integrating a rolling tread adaptation mechanism is proposed. 


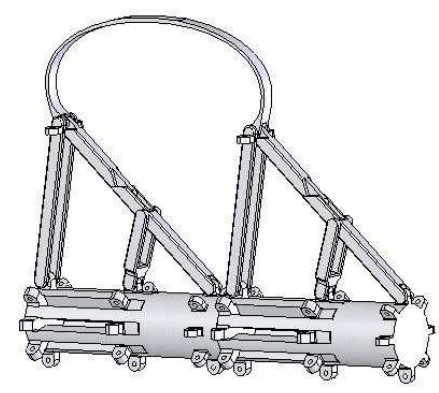

Fig. 10. Carcass-element consisting in an arched beam

\section{Acknowledgments}

This research is supported by the International Association for the Promotion of Co-operation with Scientists from the New Independent States (NIS) of the Former Soviet Union (INTAS) under grant number 4063

\section{References}

1. A. Kermurdjian, V. Gromov, V. Mishkinyuk, V. Kucherenko, and P. Sologub. Small Marsokhod Configuration. Proceedings of the 1992 IEEE International Conference on Robotics and Automation, May 1992.

2. W.W. Gan, S. Pellegrino, Closed-Loop Deployable Structures, 44th AIAA/ASME/ASCE/AHS/ASC Structures, Structural Dynamics, and Materials Conference, 7-10 April 2003, Norfolk

3. C. Hoberman, Reversibly expandable structures. USA Patent No. 4981732 , 1991.

4. S.D. Guest1, F. Kovcs, T. Tarnai and P.W. Fowler, Construction of a Mechanical Model for the Expansion of a Virus, Proc. IASS-2004, 20-24 September 2004, Montpellier, France.

5. Ph. Block, Interactive kinetic structures: Architecture with an organic trait, Joint SMArchS Colloquium / BT Seminar Series, Fall 2003

6. Gunnar Tibert, Deployable Tensegrity Structures for Space Applications, Royal Institute of Technology Department of Mechanics Doctoral Thesis Stockholm, 2002

7. S. K. Agrawal, S. Kumar, M. H. Yim, J.W. Suh Polyhedral single degree of freedom expanding structures. IEEE International Conference on Robotics and Automation (ICRA 2001); 2001 May 21-26; Seoul, Korea. Piscataway, NJ: IEEE; 2001; 4:3338-3343. 